\title{
Consensus meetings regarding uterine artery embolization and focused ultrasound in fibroid treatment: an analysis
}

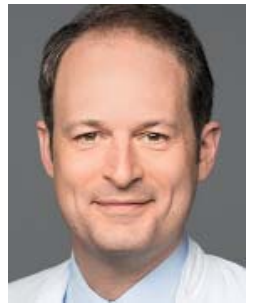

Prof. Dr. Thomas Kröncke

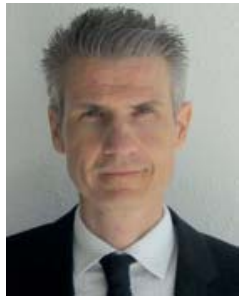

Prof. Dr. Matthias David

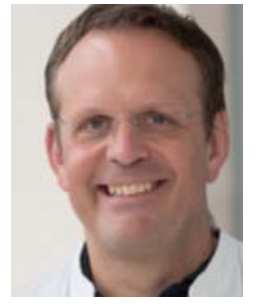

Dr. Matthias Matzko
Correspondence

Prof. Dr. Thomas Kröncke

Radiologie, Klinikum Augsburg, Stenglinstr. 2, 86156

Augsburg, Germany

Tel.: ++49/8 21/4002441

Fax: ++49/8 21/4003312

thomas.kroencke@klinikum-augsburg.de
Bibliography

DOI https://doi.org/10.1055/s-0043-108824

Published online: 2017 | Fortschr Röntgenstr 2017; 189:

508-510 @ Georg Thieme Verlag KG Stuttgart · New York

ISSN 1438-9029
On 10/16/2005, gynecology and radiology specialists met in Berlin for a consensus meeting regarding the use of uterine artery embolization (UAE; fibroid embolization) to treat fibroids [1]. The goal of this meeting was to summarize the current state of knowledge regarding fibroid embolization, which was a new treatment option at that time, and to provide recommendations regarding indication, implementation and follow-up from an interdisciplinary radiological-gynecological standpoint. In 2010, representatives from Austria and Switzerland participated in the discussion for the first time so that consensus recommendations with the support of the professional societies can now be made across borders [2]. In 2013, the consensus meetings were expanded to include an interdisciplinary dialog regarding the use of MR-guided focused ultrasound (MRgFUS [3]) in the treatment of fibroids and have since then been held every two years at the IROS, the threecountry meeting of the German, Austrian, and Swiss societies for interventional radiology [4-7].

The current edition of RöFo [8, 9] presents the results of the 3 rd consensus meeting "MRgFUS for fibroid treatment" and 6th consensus meeting "UAE for fibroid treatment" which was held on January 14, 2017.

For the 3 rd consensus meeting "MRgFUS for fibroid treatment", a selective search of the literature including topics deemed relevant by the invited participants was performed. Selected publications were included in the appendix of the consensus paper. The effects of pretreatment with ulipristal acetate, the recommended interval between MRgFUS and trying to con- ceive, the approach in the case of postinterventional discharge of fibroid material from the vagina (fibroid expulsion), the necessity of follow-ups after MRgFUS treatment, and the significance of volume reduction for symptom control were discussed based on the current literature and the experiences of the consensus participants with the method. Particular attention was given to the topic "treatment of an undetected leiomyosarcoma". The consensus participants agreed on the following formulation: “...in the informed consent discussion prior to MRgFUS, the patient should be made aware of the lack of preinterventional histological confirmation which all other organ-preserving fibroid treatment methods have in common...". In the case of suspicion of a malignancy of the uterus, MRgFUS treatment is absolutely contraindicated.

Reference to the fact that the selective progesterone receptor modulator ulipristal acetate can lead to better perfusion of fibroids so that the evaluation of the ability to treat with MRgFUS as well as the treatment itself could be unfavorably affected by the taking of ulipristal acetate was added.

With respect to "MRgFUS in patients desiring to have children", the consensus participants agreed on the basis of a lack of prospective study results that MRgFUS/HIFU treatment cannot be recommended prior to a planned pregnancy. However, if a patient wants to become pregnant after MRgFUS/HIFU treatment, a minimum interval of approximately 6 months between fibroid treatment with MRgFUS and conception is recommended.

The 6th consensus meeting "UAE for fibroid treatment" was also preceded by a selective search of the literature. Two impor- 
tant publications were included in the appendix of the consensus paper: The systematic review with a meta-analysis comparing UAE to surgical methods by van den Kooij et al. (2011) and the "Cochrane Database Review" by Gupta et al. (2014) including seven randomized controlled studies with 793 patients $[10,11]$. The 10-year data of the EMMY study [12] published in 2016 is also referenced. Based on these publications and the extensive experience of the consensus participants with fibroid embolization, the following topics were discussed: UAE in the case of an intrauterine device (IUD), pretreatment with ulipristal acetate, UAE and a desire to have children, management of "vaginal fibroid discharge" as a result of UAE. The topic "embolization of an undetected uterine sarcoma" was given special attention. The consensus participants agreed on the following new recommendation: "The total risk of an undetected uterine malignancy (including uterine sarco$\mathrm{ma}$ ) in patients undergoing surgery for a fibroid is specified between $0.09 \%$ and $0.18 \%$ in the current literature. Clinical presentation and imaging do not allow exclusion of a uterine sarcoma in particular. The decision for an organ-preserving, medicationbased, surgical, or interventional-radiological treatment option therefore should include explanation of the risks of delayed diagnosis of a sarcoma. The spreading of tumor cells after UAE has not been observed. In the case of a lack of response to treatment or a lack of a reduction in size of the leiomyoma(s), an insufficient embolization result and the presence of a uterine sarcoma must be considered as differential diagnoses...." "UAE in women desiring to have children" was a controversial topic of discussion. In a multi-step process, the majority of participants agreed to the following formulation: "Pregnancy after UAE is possible. The risk of miscarriage may be increased..." A minority of participants voted to include supplementary information so that the following phrase was added as a minority opinion: "In addition to miscarriage, abnormal placentation and peripartum bleeding may be more common after fibroid embolization (insufficient reliable data)".

As in the past, the participants of the expert meeting at this year's consensus meeting were aware that the possibilities and limits of a radiological treatment method were being discussed together with gynecology specialists who do not actually perform the procedure. This approach has already proven effective. The consensus meetings are used to formulate practical, patient-centric recommendations for performing UAE and MRgFUS and thus follow a best practice approach. It must be noted that to date both radiological treatment methods have been insufficiently included in relevant guidelines in Germany, Switzerland, and Austria in comparison to other European countries. Already in 2012, the Collège National des Gynécologues et Obstétriciens Français included UAE as a treatment option in a revision of the national guidelines regarding the treatment of uterine fibroids [13]. In the Netherlands in 2013, interdisciplinary guidelines regarding the treatment of heavy menstrual bleeding that can be caused by fibroids were adopted jointly by the Nederlandse Vereniging voor Radiologie and Nederlandse Vereniging voor Obstetrie en Gynaecologie [14]. Both evidence-based guidelines were created on a disease-related and interdisciplinary basis and with the participation of radiology specialists. This opportunity was missed in the method-based S3 guidelines regarding hysterectomy in benign diseases published in 2015 by the Deutsche Gesellschaft für Gynäkologie und Geburtshilfe (DGGG) [15]. Although guidelines regarding the indication for and methodology of a surgical gynecological procedure were in the foreground here, it must be noted that hysterectomy in benign diseases is indicated in $60 \%$ of cases because of uterine fibroids. Therefore, minimally invasive alternative methods are of particular importance in this regard. Therefore, it is unfortunate that neither the Deutsche Röntgengesellschaft (DRG) nor the Deutsche Gesellschaft für Interventionelle Radiologie (DeGIR) was included in the guideline creation process.

The current consensus papers regarding uterine artery embolization and focused ultrasound in fibroid treatment are published both in RöFo and in the "Zeitschrift für Geburtshilfe und Frauenheilkunde" (GebFra). The DRG, DeGIR, and DGGG have supported both consensus meetings logistically and financially due to which may be seen as a desire of the societies to continue and improve the interdisciplinary dialog between radiology and gynecology with respect to fibroid treatment.

\section{Conflict of Interest}

The authors declare that they have no conflict of interest.

\section{Literatur}

[1] Kröncke T, David M, Ricke J et al. Uterusarterien-Embolisation zur Myombehandlung. Ergebnisse eines radiologisch-gynäkologischen Expertentreffens. Fortschr Röntgenstr 2006; 178: 453-454

[2] Kröncke T, David M et al. Uterusarterienembolisation (UAE) zur Myombehandlung - Ergebnisse des 3. radiologisch-gynäkologischen Expertentreffens. Fortschr Röntgenstr 2010; 182: 615-617

[3] Beck A, David M, Kröncke T. Magnetresonanz-geführter fokussierter Ultraschall zur Myombehandlung - Ergebnisse des ersten radiologischgynäkologischen Expertentreffens. Fortschr Röntgenstr 2013; 185: 464-466

[4] Kröncke T, David M. Magnetic Resonance Guided Focused Ultrasound for Fibroid Treatment - Results of the Second Radiological Gynecological Expert Meeting. Fortschr Röntgenstr 2015; 187: 480-482

[5] Kröncke T, David M. Magnetic Resonance Guided Focused Ultrasound for Fibroid Treatment - Results of the Second Radiological Gynecological Expert Meeting. Geburtshilfe Frauenheilkd 2015; 77: 436-438

[6] Kröncke T, David M. Uterine Artery Embolization (UAE) for Fibroid Treatment - Results of the 5th Radiological Gynecological Expert Meeting. Fortschr Röntgenstr 2015; 187: 483-485

[7] Kröncke T, David M. Uterine Artery Embolization (UAE) for Fibroid Treatment - Results of the 5th Radiological Gynecological Expert Meeting. Geburtshilfe Frauenheilkd 2015; 75: 439-441

[8] Kröncke T, David M. Uterine Artery Embolization (UAE) for Fibroid Treatment: Results of the 6th Radiological Gynecological Expert Meeting. Fortschr Röntgenstr 2017; 189: 511-514

[9] David M, Matzko M. MR-Guided Focused Ultrasound in Fibroid Treatment - Results of the 3rd Radiological-Gynecological Expert Meeting. Fortschr Röntgenstr 2017; 189: 515-518

[10] van der Kooij SM, Bipat S, Hehenkamp WJK et al. Uterine artery embolization versus surgery in the treatment of symptomatic fibroids: a systematic review and metaanalysis. Am J Obstet Gynecol 2011; 205: 317. e1-e18 
[11] Gupta JK, Sinha A, Lumsden MA et al. Uterine artery embolization for symptomatic uterine fibroids. Cochrane Database of Systematic Reviews 2014; 12: Art. No.: CD005 073. DOI: 10.1002/14651858.CD005073.pub4

[12] de Bruijn AM, Ankum WM, Reekers JA et al. Uterine artery embolization vs hysterectomy in the treatment of symptomatic uterine fibroids: 10year outcomes from the randomized EMMY trial. Am J Obstet Gynecol 2016; 215: 745.e1-e12

[13] Nederlandse Vereniging voor Radiologie/Nederlandse Vereniging voor Obstetrie en Gynaecologie. Hevig menstrueel bloedverlies (HMB). 2013.
Online im Internet: http://richtlijnendatabase.nl/richtlijn/hevig_menstrueel_bloedverlies/hevig_menstrueel_bloedverlies_-_startpagina. html (Stand 25.3.2017)

[14] Marret $\mathrm{H}$ et al. Therapeutic management of uterine fibroid tumors: updated French guidelines. Eur J Obstet Gynecol Reprod Biol 2012; 165 : 156 - 164 Epub 2012 Aug 29

[15] Indication and technics of hysterectomy for benigne diseases. Guideline of the German Society of Gynecology and Obstetrics (AWMF Registry No. 015/ 077, March 2015. http://www.awmf.org/leitlinien/detail/I/015-070.html 